Methods Spirometry measurements were performed and DLCO was measured. The final data analysis was conducted on 57 diabetics (mean age $14.4+3.09$ years, 31 males) and 40 healthy controls (mean age $13.6+2.2$ years, 19 males).

Results Although FVC, FEV1, FEV1/FVC of diabetics were lower than in control, significant statistical analysis was found only for FEF 25-75. Statistically significant differences between diabetic and control girls was noted with lower FEV1, lower FEV1/FVC, lower FEF25-75 and reduced DLCO/VA values in diabetic girls. Almost no correlation was found for diabetes duration, HbA1c, HRV indices and pulmonary function variables.

Conclusions In conclusion, the results of our study indicate subclinical lung impairment in children with T1DM, with significantly reduced FEF 25-75 compared to control subjects, indicating early small airway obstructive pattern. In this study, statistically significant differences between diabetic and control girls was noted, suggesting obstructive airway disease, according to the spirometric evaluation, but restrictive derangement indicated by reduced DLCO/VA. Since total lung capacity was not measured in our study, we can not talk about a restrictive pattern according to reduced DLCO/VA, but gender appeared a significant determinant for pulmonary dysfunction.

\section{GASTROESOPHAGEAL PH CHARACTERIZES FUNCTIONAL AIRWAYS RESPONSE IN ASTHMATIC CHILDREN}

doi:10.1136/archdischild-2012-302724.0667

C Pacchiarotti, M Barreto, A Bozzone, M Campisano, S Fedeli, A Macari, F La Penna, F Guglielmi, MP Villa. Sapienza University of Roma, Roma, Italy

Background Gastroesophageal acidity $(\mathrm{GE} \mathrm{pH})$ could be related to lung function and airway response to exercise in children with lower airways disease.

Aims To compare GE pH with lung function before and after exercise in asthmatic and non-asthmatic outpatients with recurrent respiratory symptoms.

Methods 16 asthmatic and 15 non-asthmatic patients (aged 4 5-15.7 yr; M/F 23/8) did lung function before and after 24-h GE pH monitoring $\left(\mathrm{GE} \mathrm{pH}_{24}\right)$. Subjects also undergone exercise-testing (treadmill) 1 hour before GE catheter removal. GE pH was also analysed for 6-minute intervals each (before, during and after exercise).

Results GE $\mathrm{pH}{ }_{24}$ levels did not correlate with exercise outcomes, nor yielded statistical differences between patient groups. Instead, GE $\mathrm{pH}_{24}$ correlated positively with baseline $\mathrm{FEV}_{1} \%$ in asthmatic subjects $(r=0.66, p=0.006)$ whereas correlated negatively in nonasthmatic subjects $(\mathrm{r}=-0.61, \mathrm{p}=0.016)$. Median (interquartile range, IOR) values of GE $\mathrm{pH}$ fall during exercise in asthmatic but not in non-asthmatic children (-4.64, IOR:10.2 vs 0.00, IOR:5.64, p=0.033). Conversely, GE $\mathrm{pH}$ values increased 1 hour after exercise only in asthmatic children (5.80, IOR:7.73 vs 0.00, IQR:9.82, $\mathrm{p}=0.012$ ).

Conclusion Our data suggest a characteristic relationship between $\mathrm{GE} \mathrm{pH}$, lung function and airway response to exercise in asthmatic children; whether GE $\mathrm{pH}$ is cause or consequence of these bronchial changes remains to be established.

\section{YOUNGER CHILDREN ARE MORE RELIABLE IN ESTIMATING THE SEVERITY OF ASTHMA ATTACK COMPARING TO PARENTS AND OLDER CHILDREN}

doi:10.1136/archdischild-2012-302724.0668

${ }^{1} \mathrm{D}$ Stamatovic, ${ }^{2} \mathrm{~K}$ Starinac, ${ }^{3} \mathrm{Z}$ Zivkovic, ${ }^{1} \mathrm{~A}$ Stamatovic. ${ }^{1}$ Private Pediatric Practice 'Primum Vivere'; 'Dispensary for Children Health Care, Krusevac; ${ }^{3}$ Faculty of Medicine, Pristina University, Kosovska Mitrovica, Serbia
Background and Aims Many studies emphasize that child's perception of asthma symptoms is not reliable.

We assessed correlation between objective and subjective asthma attack estimation and analyzed factors that affect objectivity.

Methods Independently from parents, 33 children ages 5-18 years estimated asthma attack severity from $0-10$ by visual analog scale score (VASS) - subjective estimation. Objective estimation for each child was done in two ways: comparing absolute values of lung function parameters (LFP) with Zapletal's norms (ZN): LFP\%ZN by Jeager Flowscreen spirometer, and with individual best values during optimal disease control, individual norms (IN): LFP\%IN. We analyzed the correlation between subjective and objective estimations.

Results VASS of children and parents were not in mutual correlation. VASS of children and parents were not in correlation with spirometric estimation (LFP\%ZN). In younger children, correlation becomes statistically significant if we use IN instead of $Z N$ (LFP\%IN): $\mathrm{r}=-0.45, \mathrm{p}=0.049$ (FEV1); $\mathrm{r}=-0.52, \mathrm{p}=0.020$ (MEF50); $r=-0.6, p=0.005$ (MEF25). VASS of their parents were not in correlation with LFP\%IN. In 15 of 20 cases, IN of younger children were higher than $Z \mathrm{~N}$, thus more valid. On the contrary, IN of older children were mainly below ZN (in 10 of 13), thus less reliable for estimation. In this group there was no correlation regardless of applied norm and whether the estimation was done by child or a parent.

Conclusions Children ages 5-10 years are more reliable in estimating the severity of asthma attack than older children and their parents who are adapted to lower child's possibilities.

\section{MONITORING THE ASTHMATIC CHILDREN, A PROSPECTIVE STUDY}

doi:10.1136/archdischild-2012-302724.0669

${ }^{1} \mathrm{MBI}$ Octavia, ${ }^{2} \mathrm{~N}$ Bogdan, ${ }^{3} \mathrm{NM}$ Leonida, 'S Iulia, ${ }^{4} \mathrm{M}$ Rodica, ${ }^{5} \mathrm{H}$ Mirela, ${ }^{6} \mathrm{~S}$ Claudia, ${ }^{7} \mathrm{M}$ lonela, ${ }^{8} \mathrm{~K}$ Otto, ${ }^{5} \mathrm{M}$ Melaniea, ${ }^{2} \mathrm{~N}$ Cristian. ${ }^{1}$ Pediatric Clinic; ${ }^{2}$ Research, Pediatric Hospital, Lucian Blaga University Sibiu; ${ }^{P}$ Pediatric Hospital, Lucian Blaga University Sibiu; "Pneumology; ${ }^{5}$ Laboratory Research, Pediatric Hospital, Lucian Blaga University Sibiu; 'Research, Pediatric Hospital Sibiu; '7pplied Informatics, Faculty of Science, Lucian Blaga University Sibiu; ${ }^{8}$ Agricultural Sciences and Food Engineering, Faculty of Agricultural Sciences, Food Industry and Environment Protection, Lucian Blaga University Sibiu, Sibiu, Romania

Background Spirometry and biomarkers such as immunoglobulin E (IgE) levels, fractional exhaled nitric oxide concentration (FeNO) have been proposed for assessing the risk of future adverse events in Expert Panel Report 3 (US National Asthma Education and Prevention Program).

Objectives Evaluating the interrelationship between spirometry parameters and/or biomarkers levels (IgE, FeNO, blood eosinophils percentage) and specific symptoms in asthmatic children between hospitalization episodes.

Material and Methods 40 asthmatic pacients were evaluated performing spirometry and measuring biological parameters (Ig E levels, blood eosinophils, Fe NO). Symptoms like cough, dispnoea, wheezing described in patients diaries were analysed in correlation with the spirometric and biological parameters using t-Test, MannWhitney test, Pearson correlations. For each symptom analysed, every time two groups have emerged (with symptoms or without symptoms).

Results Blood eosinophils were different for each symptom, $\mathrm{p}<0.05$ comparing each time the groups. The tendency for positive corelations $\mathrm{p}=0.08$ was noticed between FeNO and FEV1 (forced expiratory vital capacity). Positive corelations, $\mathrm{p}<0.05$ were found between studied parameters, most of the time in the same group (either the group with symptoms or the group without symptoms). 
Conclusions Blood eosinophils and IgE levels may be regarded more as global predictors but FEV1 and FeNO may be considered more accurate predictors in risk assessment of future adverse events.

\section{EXHALED NITRIC OXIDE AS A PREDICTOR FOR EXACERBATION IN CHILDHOOD ASTHMA - IS IT USEFUL?}

doi:10.1136/archdischild-2012-302724.0670

'R Diaconu, 'L Stanescu, ${ }^{2} \mathrm{C}$ Diaconu. ${ }^{1}$ Pediatrics, University of Medicine and Pharmacy Craiova; ${ }^{2}$ Sports Medicine, Emergency County Hospital Craiova, Craiova, Romania

Aims Currently, the asthma control is based on symptoms and lung function indices. The inflammatory markers like exhaled nitric oxide (FeNO) may provide additional data for asthma management. We aimed to correlate the FeNO levels with asthma exacerbations in children admitted to our pediatric department.

Methods 104 children (57 boys), aged 5 to 11, were enrolled to our 12 month survey. The monthly follow up visits comprised in clinical exam, childhood asthma control test (C-ACT), spirometry and FeNO measurement (NioxMino, Sweden). The analysis was done using the chi squared test.

Results 68 children experienced a total of 114 exacerbations during the survey. Only 23 exacerbations were associated with positive FeNO values (over $25 \mathrm{ppB}$ ), compared to 67 C-ACT positive: $\mathrm{p}=0.000 ; \mathrm{OR}=0.17(0.09-0.31) ; 44$ spirometry positive: $\mathrm{p}=0.001$ $\mathrm{OR}=0.40(0.22-0.72)$ and 34 clinical positive findings: $\mathrm{p}=0.04$ $\mathrm{OR}=0.59(0.32-1.09) .21$ of the positive FeNO cases (91\%) had high values (over $50 \mathrm{ppB}$ ). On the other hand, 87 cases showed an increase in FeNO measurements without clinical exacerbation.

Conclusions Exhaled nitric oxide poorly correlates with asthma exacerbations, compared to "classical tools". High values may be useful as a predictor, but the sensitivity and specificity are still uncertain.

\section{EXHALED NITRIC OXIDE AND PULMONARY FUNCTION IN CHILDREN WITH ALLERGIC ASTHMA}

doi:10.1136/archdischild-2012-302724.0671

'A Omerčahïe Dizdareviç' ${ }^{2}$ S MesihoviéEinarević. 'Allergology, Rheumatology and Clinical Immunology; ${ }^{2}$ Cardiology, Children's Hospital Sarajevo, Sarajevo, Bosnia-Herzegovina

Background and Aims Nitric oxide (NO) is a marker of eosinophilic inflammation in airways and can be measured in exhaled air Fractional exhaled nitric oxide (FeNO) is elevated in allergic asthma. Children with asthma and normal spirometry (FEV1\%) can have an inflammation of airways. Inhaled steroid therapy decreases FeNO levels. The aims of this study is to analyze the values of FeNO and FEV1\% in children with allergic asthma (steroid naïve and undertaking inhaled steroid therapy).

Methods Thirty steroid naïve children with asthma, aged 5-15 years ( $<10$ years $n=20,>10$ years $n=10)$ and thirty children with asthma, undertaking inhaled steroid therapy longer than 1 month, aged $5-15$ years $(<10$ years $18,>10$ years 12$)$, were included. Recent respiratory infections were negative in all groups. On line technique was performed in measuring FeNO using a cheiloiluminescent analyser Niox, Aerocrine-Sweden, according to ERS/ATS recommendations. Spirometry was performed by standardized procedure.

Results FeNO levels were significantly higher (Kruskal-Wallis test) in steroid naïve group $(\mathrm{C}=47.45)$ vs undertaking therapy group $(C=11.15)$. Significant difference between these groups (Mann-Whitney test) was confirmed( $Z=6.56$; $p=0,0001) .98 \%$ children in steroid naïve group had normal spirometry (FEV1\%>80\%). Significant difference in FEV1\% (Mann-Whitney test), between steroid naïve and undertaking therapy group, was found $(Z=-3.86 ; p=0.0001)$.

Conclusions Steroid naive children with asthma had significant higher values of FeNO vs children undertaking inhaled steroid therapy. Significant difference in FEV1\% was found in these two groups. In our study, steroid naive children with asthma and normal FEV1\% had eosinophilic inflammation in airways.

\section{FENO AND ASTHMA CONTROL}

doi:10.1136/archdischild-2012-302724.0672

F Cora, M Moiceanu, E Buzoianu, V Hurduc, DA Plesca. Pediatrics, Children's Hospital 'Dr.Victor Gomoiu', Bucharest, Romania

Background and Aims Asthma is a chronic inflammatory disease of the lower airways, whose treatment is conducted by guidelines in use, depending on clinical markers of disease control (ACT=asthma control test score) and spirometric values. Due to situations in which there is discrepancy between the two categories of parameters, we aimed this study to examine whether FENO measurement may be an additional argument in guiding the treatment.

Method The prospective study lasted five months and included 30 patients diagnosed as moderate persistent asthma, aged 5-17 years, nonsmokers; ACT score, FEV1 and FENO were assessed.

Results 12 patients had ACT> 19, normal FEV1 values and FENO $<20 \mathrm{ppb}$.

18 patients had ACT < 19; 9 of them had normal FEV1 values and 16 had FENO values $>32 \mathrm{ppb}$

Conclusion FENO value correlates better than FEV1 with clinical asthma control score, so it can be an additional marker in therapeutic decision.

\section{PRE AND POST BRONCHODILATOR AIRWAY RESISTANCE VALUES IN CHILDREN WITH ASTHMA USING AIRFLOW PERTURBATION DEVICE (APD)}

doi:10.1136/archdischild-2012-302724.0673

${ }^{1,2} \mathrm{~N}$ Rostami, ${ }^{3} \mathrm{M}$ Bautista, ${ }^{4} \mathrm{~A}$ Johnson, ${ }^{5} \mathrm{~J}$ Vossoughi, ${ }^{6} \mathrm{M}$ Kezsler. 'Pediatrics, Georgetown University Hospital, Washington, DC: ${ }^{2}$ Pediatrics, Sinai Hospital, Baltimore, Baltimore, MD; ${ }^{3}$ Pediatrics, Georgetown University Hospital, Washington DC, DC; ${ }^{4}$ Bioengineering, University of Maryland, College Park; ${ }^{5}$ Engineering, Engineering and Scientific Research Associates, Olney, MD; ${ }^{6}$ Pediatrics, Brown University, Women and Infants Hospital, Providence, RI, USA

Background Asthma is the most common chronic disease of childhood and pulmonary function testing plays an important role in assessment and management of children with asthma. Pre and post bronchodilator spirometry test is the most common pulmonary function measurement that is utilized in the diagnosis of asthma.

Methods Respiratory resistance using APD was measured prior and 20 minutes after Albuterol in children with asthma who presented to the Pediatric Pulmonary Clinic at GUH.

Results A total of 30 children with asthma (mean age: 10.6; range: 5.6-17) including 14 female and 16 male participated in the study. The respiratory resistance values by APD ranged from 3.34-8.22 $\mathrm{CmH} 2 \mathrm{O} / \mathrm{L} / \mathrm{S}$ (mean 5.27) for pre bronchodilator treatment and 2.37-6.95 (mean 4.33) for post treatment. All 30 children showed decrease in respiratory resistance as measured by APD after bronchodilator therapy. The highest value of resistance was 8.22 which was seen in the youngest child (5.6 yo) and the lowest resistance was 3.34 which was seen in an older child (16 yo). These results are consistent with the findings that airway resistance decreases after bronchodilator therapy in patients with asthmahas been developed to measure airway resistance noninvasively and without need of extensive coordination. The APD is a simple and portable device that can be used easily by patients of all ages.

Conclusions APD is a simple, convenient, effortless, and easy to use device that may be a used as a valuable tool in evaluation of children with asthma.

This abstract is funded by NIH-NHLBI Grant \# 2R44HL0780 55-02A1 